received rituximab treatment in response to a severe obstructive ventilatory defect and, thus, our results do not preclude the potential efficacy of rituximab in less severe BO. Further studies are needed to determine whether rituximab is a valuable therapeutic option in chronic lung GVHD.

\section{G. Lorillon*, M. Robin", V. Meignin ", P. Ribaud", B. Lescoeur ${ }^{+}$, D. Gossot ${ }^{\S}$, G. Socié\#, A. Tazi* and A. Bergeron*}

*Service de Pneumologie, "Service d'Hématologie-Greffe, 'Service de Pathologie, Hôpital Saint-Louis, Université Paris 7, UFR Denis Diderot; Assistance Publique-Hôpitaux de Paris, +Service d'Hématologie Pédiatrique, Hôpital Robert Debré, Université Paris 7, UFR Denis Diderot; Assistance PubliqueHôpitaux de Paris, and ${ }^{\S}$ Service de Chirurgie Thoracique, Institut Mutualiste Montsouris, Paris, France.

Correspondence: A. Bergeron, Service de Pneumologie, Hôpital Saint-Louis, 1 avenue Claude Vellefaux, 75475, Paris cedex 10, France. E-mail: anne.bergeron-lafaurie@sls.aphp.fr

Statement of Interest: None declared.

\section{REFERENCES}

1 Filipovich AH, Weisdorf D, Pavletic S, et al. National Institutes of Health consensus development project on criteria for clinical trials in chronic graft-versus-host disease: I. Diagnosis and staging working group report. Biol Blood Marrow Transplant 2005; 11: 945-956.
2 Williams KM, Chien JW, Gladwin MT, et al. Bronchiolitis obliterans after allogeneic hematopoietic stem cell transplantation. JAMA 2009; 302: 306-314.

3 Dudek AZ, Mahaseth H, DeFor TE, et al. Bronchiolitis obliterans in chronic graft-versus-host disease: analysis of risk factors and treatment outcomes. Biol Blood Marrow Transplant 2003; 9: 657-666.

4 Ratanatharathorn V, Ayash L, Reynolds C, et al. Treatment of chronic graft-versus-host disease with anti-CD20 chimeric monoclonal antibody. Biol Blood Marrow Transplant 2003; 9: 505-511.

5 Kharfan-Dabaja MA, Mhaskar AR, Djulbegovic B, et al. Efficacy of rituximab in the setting of steroid-refractory chronic graft-versushost disease: a systematic review and meta-analysis. Biol Blood Marrow Transplant 2009; 15: 1005-1013.

6 Kim SJ, Lee JW, Jung CW, et al. Weekly rituximab followed by monthly rituximab treatment for steroid-refractory chronic graftversus-host disease: results from a prospective multicenter phase II study. Haematologica 2010; 95: 1935-1942.

7 Yoshihara S, Yanik G, Cooke KR, et al. Bronchiolitis obliterans syndrome (BOS), bronchiolitis obliterans organizing pneumonia (BOOP), and other late-onset noninfectious pulmonary complications following allogeneic hematopoietic stem cell transplantation. Biol Blood Marrow Transplant 2007; 13: 749-759.

8 McGonagle D, Tan AL, Madden J, et al. Successful treatment of resistant scleroderma-associated interstitial lung disease with rituximab. Rheumatology (Oxford) 2008; 47: 552-553.

9 Borie R, Debray MP, Laine C, et al. Rituximab therapy in autoimmune pulmonary alveolar proteinosis. Eur Respir J 2009; 33: 1503-1506.

10 Vandenbroucke E, Grutters JC, Altenburg J, et al. Rituximab in life threatening antisynthetase syndrome. Rheumatol Int 2009; 29: 1499-1502.

\title{
Exclusive viral wheeze and allergic wheeze: evidence for discrete phenotypes
}

\section{To the Editors:}

There is a broad consensus that childhood wheezing illness consists of several distinct disease entities, but there is no agreement on their number or underlying mechanisms [1]. Commonly used phenotypic classifications are based on clinical or epidemiological criteria [2-6], and there has been little work focusing on causal mechanisms $[1,6,7]$.

Trigger factors for wheezing episodes might be indicators of such mechanisms. In young children, wheeze is commonly triggered by respiratory viral infections (colds), physical factors associated with increased breathing (exercise, laughing, crying and excitement) or allergens (aeroallergens and food allergens). These triggers are increasingly used to define asthma phenotypes in young children [3,5]. Despite this, there are few data on the way in which these triggers change in importance with age or whether different classes of triggers are independent. A close association between different classes of triggers in the same children would suggest a common underlying mechanism while a lack of association might reflect independent causal mechanisms. In this analysis, we describe changes in the prevalence of different parent-reported triggers of wheeze by age in 1-9 yr olds and report statistical associations between different classes of triggers (exercise, allergens and infection).

We used data from the Leicestershire Cohort Studies, a population-based random sample of children living in Leicestershire, UK [8]. The children were recruited in 1998 at an age of 1-4 yrs and were followed up in 1999, 2001, 2003 and 2006. In each survey, their parents completed a postal questionnaire asking detailed questions about respiratory symptoms during the previous 12 months and environmental exposures. The Leicestershire Health Authority Research Ethics Committee (Leicester, UK) approved the study.

For ages 1, 4, 6 and 9 yrs, we assessed the prevalence of different classes of triggers of wheeze and their combinations among children reporting any wheeze in the previous 12 months. We considered the following classes of triggers reported by parents: exercise (running/playing and/or laughing/crying/excitement), 


\begin{tabular}{|c|c|c|c|c|c|}
\hline \multirow[t]{3}{*}{ TABLE 1} & \multicolumn{5}{|c|}{$\begin{array}{l}\text { Proportion of children with current wheeze who } \\
\text { reported different trigger factors (exercise, } \\
\text { allergens and infection) by age }\end{array}$} \\
\hline & & \multicolumn{4}{|c|}{ Age yrs } \\
\hline & & 1 & 4 & 6 & 9 \\
\hline \multicolumn{2}{|l|}{ Subjects $n$} & 1447 & 612 & 471 & 290 \\
\hline \multicolumn{2}{|c|}{$\begin{array}{l}\text { Any trigger (exercise, } \\
\text { allergens or infection) }\end{array}$} & 95.7 & 94.6 & 95.3 & 94.8 \\
\hline \multicolumn{2}{|l|}{ Exercise } & 35.5 & 44.0 & 48.6 & 36.9 \\
\hline \multicolumn{2}{|l|}{ Allergens } & 7.5 & 24.8 & 34.8 & 62.4 \\
\hline \multicolumn{2}{|l|}{ Infection } & 94.1 & 90.0 & 89.0 & 81.0 \\
\hline \multicolumn{6}{|c|}{ Combination of triggers } \\
\hline \multicolumn{2}{|l|}{ Exercise } & 1.2 & 2.5 & 1.7 & 2.1 \\
\hline \multicolumn{2}{|l|}{ Allergens } & 0.2 & 1.1 & 3.4 & 9.0 \\
\hline \multicolumn{2}{|l|}{ Infection } & 57.1 & 41.3 & 33.6 & 21.0 \\
\hline \multicolumn{2}{|c|}{ Exercise and allergens } & 0.1 & 1.0 & 1.3 & 2.8 \\
\hline \multicolumn{2}{|c|}{ Exercise and infection } & 29.9 & 26.0 & 25.3 & 9.3 \\
\hline \multicolumn{2}{|c|}{ Allergens and infection } & 2.8 & 8.2 & 9.8 & 27.9 \\
\hline \multicolumn{2}{|c|}{ Exercise, allergens and infection } & 4.3 & 14.5 & 20.4 & 22.8 \\
\hline
\end{tabular}

Data are presented as \%, unless otherwise stated. Exercise: running/playing and/or laughing/crying/excitement; allergens: food/drink and/or pollen/grass; infection: colds.

allergens (food/drink and/or pollen/grass) and infection (colds). For each age, we assessed associations between the three classes of triggers using log-linear models [9], which included main effects for each of the classes and interaction terms for each pair of classes: exercise and allergens; exercise and infection; and allergens and infection. For any pair of trigger classes, A and B, these models yield the odds ratio (OR) for having $A$ when $B$ is present compared to when $B$ is absent (the roles of $A$ and $B$ can be interchanged). For each pair of classes, we tested whether this OR was equal to 1 , meaning that the presence of one trigger did not affect the presence of the other (independence of the classes). The data were analysed using STATA, version 11.0 (StataCorp, Austin, TX, USA) and models were fitted using the "Poisson" command.

Respiratory symptom information was available for 4,102, 3,143, 3,038 and 1,858 children aged 1, 4, 6 and 9 yrs, respectively. Current wheeze (in the previous 12 months) was reported by 36, 20, 16 and $16 \%$ of these children, respectively. We found a steep decrease with age in the proportion of children with current wheeze who reported that their wheezing episodes were triggered by infection only (from $57 \%$ at age 1 yr to $21 \%$ at age 9 yrs), or by both infection and exercise (from $30 \%$ to $9 \%$, respectively) (table 1 ). In contrast, we found an increase with age in the proportion of wheezers reporting that episodes were triggered by allergens only (from $0.2 \%$ to $9 \%$ ), allergens and exercise (from 0.1 to $3 \%$ ), or all three triggers (from $4 \%$ to $23 \%$ ) at age $1 \mathrm{yr}$ and 9 yrs, respectively (table 1). The log-linear models with interaction terms for each pair of classes fitted the data reasonably well (all p-values for goodness of fit were $>0.1$ ) (table 2). We found a significant positive association between exercise and allergens at ages 1, 4 and 6 yrs, and between exercise and infection at ages 1, 6, and 9 yrs. The triggers allergens and infection were not associated with each other at ages 1,4 and 9 yrs; the association at age 6 yrs tended to be negative (table 2).

The results of this large, population-based cohort study showed considerable age-related changes in the relative importance of trigger factors for wheeze in children, which should be considered in clinical or epidemiological studies, for instance when designing questionnaires or defining inclusion criteria for a trial. We found significant positive associations between exercise- and allergen-related triggers, and between exercise- and infection-related triggers. For each of these pairs, the odds for one trigger class were two to three times higher in the presence of the other class than in its absence. No positive associations were found between allergen- and infectionrelated trigger factors. This strengthens the body of evidence that suggests that viral wheeze and allergen-induced (often

\section{TABLE 2 Association between different classes of triggers}

\begin{tabular}{|c|c|c|c|c|c|c|c|c|}
\hline \multirow[t]{2}{*}{ Interaction terms } & \multicolumn{8}{|c|}{ Age yrs } \\
\hline & \multicolumn{2}{|c|}{1} & \multicolumn{2}{|c|}{4} & \multicolumn{2}{|c|}{6} & \multicolumn{2}{|c|}{9} \\
\hline Exercise $\times$ allergens & 2.86 & $<0.001$ & 2.72 & $<0.001$ & 2.50 & $<0.001$ & 1.60 & 0.071 \\
\hline GOF p-value $\#$ & \multicolumn{2}{|c|}{0.829} & \multicolumn{2}{|c|}{0.543} & \multicolumn{2}{|c|}{0.138} & \multicolumn{2}{|c|}{0.211} \\
\hline
\end{tabular}

Coefficients and p-values of interactions terms between pairs of triggers are shown. Exercise: running/playing and/or laughing/crying/excitement; allergens: food/drink and/or pollen/grass; infection: colds. The model included main effects for exercise, allergens and infection, and the presented interaction terms between classes of triggers. OR 1 means that the presence of one trigger does not affect the presence of the other (independence of the classes). GOF: goodness of fit. \#: p-values close to 1 indicate good fit while $p<0.1$ indicates poor fit; GOF tests are based on the deviance statistic and compare the presented models with the saturated models that include three-way interaction. 


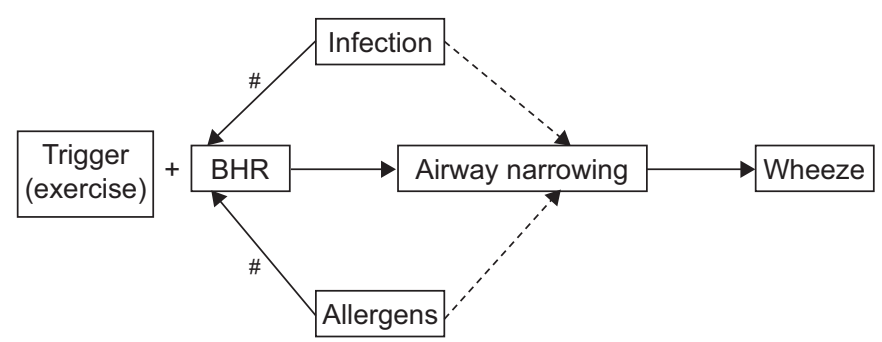

FIGURE 1. Triggers and inducers: model of possible mechanisms. BHR: bronchial hyperresponsiveness. ${ }^{\#}$ : in susceptible individuals.

called multiple-trigger) wheeze are indeed distinct disease entities $[3-5,10]$. However, a clear limitation of the study is the fact that the results are based on parental report of triggers. Replication of the study or the analysis using alternative methods of documentation would be beneficial.

Our findings provide support for an old concept proposing that infection and allergy can cause airway narrowing in susceptible individuals, either by acting directly (as trigger factors) or by induction of bronchial hyperresponsiveness (as inducing factors). Exercise, in contrast, is merely a trigger, which leads to airway narrowing only in the presence of bronchial hyperresponsiveness caused by other factors (fig. 1). Finally and most importantly, our observation that there was no evidence of dependence between viral and allergic triggers suggests that the mechanisms underlying allergen- and infection-related wheeze might be independent. This supports the notion that exclusive viral wheeze and allergic wheeze are distinct phenotypes which differ in their aetiology [10]. This work should lead to further metabolomic and physiological studies in order to confirm the characteristics of different phenotypes of wheezing disease in young children.

M-P.F. Strippoli*, B.D. Spycher*, A.M. Pescatore*, C.S. Beardsmore ${ }^{\#}$, M. Silverman ${ }^{\#}$ and C.E. Kuehni*

*Institute of Social and Preventive Medicine, University of Berne, Berne, Switzerland, and "Division of Child Health, Dept of Infection, Immunity and Inflammation, University of Leicester, Leicester, UK.
Correspondence: C.E. Kuehni, Institute of Social and Preventive Medicine (ISPM), University of Berne, Finkenhubelweg 11, CH-3012 Berne, Switzerland. E-mail: kuehni@ispm.unibe.ch

Support statement: This study was funded by Asthma UK (grant 07/048) and the Swiss National Science Foundation (SNF 3200B0122341 and PDFMP3-123162).

Statement of Interest: None declared.

Acknowledgements: We thank the parents of Leicestershire children for completing the questionnaires and T. Davis (Specialist Community Child Health Services, Leicester City Primary Care Trust, Leicester, UK) for his assistance with the Child Health Database.

\section{REFERENCES}

1 Spycher BD, Silverman M, Kuehni CE. Phenotypes of childhood asthma: are they real? Clin Exp Allergy 2010; 40: 1130-1141.

2 Martinez FD. Viral infections and the development of asthma. Am J Respir Crit Care Med 1995; 151: 1644-1647.

3 Brand PL, Baraldi E, Bisgaard H, et al. Definition, assessment and treatment of wheezing disorders in preschool children: an evidence-based approach. Eur Respir J 2008; 32: 1096-1110.

4 Spycher BD, Silverman M, Brooke AM, et al. Distinguishing phenotypes of childhood wheeze and cough using latent class analysis. Eur Respir J 2008; 31: 974-981.

5 Sonnappa S, Bastardo CM, Wade A, et al. Symptom-pattern phenotype and pulmonary function in preschool wheezers. J Allergy Clin Immunol 2010; 126: 519-526.

6 Henderson J, Granell R, Heron J, et al. Associations of wheezing phenotypes in the first 6 years of life with atopy, lung function and airway responsiveness in mid-childhood. Thorax 2008; 63: 974-980.

7 Spycher BD, Silverman M, Barben J, et al. A disease model for wheezing disorders in preschool children based on clinicians' perceptions. PLoS One 2009; 4: e8533.

8 Kuehni CE, Brooke AM, Strippoli M-PF, et al. Cohort profile: the Leicester respiratory cohorts. Int J Epidemiol 2007; 36: 977-985.

9 Sobel ME. The analysis of contingency tables. In: Arminger G, Clogg CC, Sobel ME, eds. Handbook of Statistical Modelling for the Social and Behavioural Sciences. New York, Springer, 1995; pp. 251-310.

10 Silverman M, Grigg J, Mc Kean M. Virus-induced wheeze in young children - a separate disease? In: Johnston S, Papadopoulos $\mathrm{N}$, eds. Respiratory Infections in Allergy and Asthma. New York, Informa Healthcare, 2002; pp. 427-471.

DOI: $10.1183 / 09031936.00004111$

\section{Who misses the second step of evaluation in tuberculosis contact screening?}

To the Editors:

Assessment of people likely to have been recently infected with Mycobacterium tuberculosis is important because of the risk to these people of progressing to active tuberculosis (TB) within 1-2 yrs [1]. In Portugal, contact investigation is an integral part of the TB control programme, enabling the identification and treatment of individuals with latent TB infection (LTBI), thus preventing active TB.

National guidelines require a two-step evaluation of pulmonary $\mathrm{TB}$ contacts, with the first step being performed at the 